\title{
Efficacy, safety and phytochemistry of medicinal plants used for the management of diabetes mellitus in Ethiopia: a systematic review
}

\author{
Serawit Deyno ${ }^{1,2^{*}}$, Kassahun Eneyew ${ }^{3}$, Sisay Seyfe ${ }^{3}$ and Elias Wondim ${ }^{4}$
}

\begin{abstract}
Background: Despite tremendous developments in synthetic medicine, medicinal plants are still commonly used for the management of diabetes mellitus. This study synthesized scientific evidence on commonly used medicinal plants for the management of diabetes mellitus (DM) in Ethiopia.

Methods: Databases (PubMed, Cochrane, CINAHL and Google Scholar) have been thoroughly sought and evidence was synthesized.

Results: Thirty studies conducted anti-diabetic activities studies on 19 medicinal plants in Ethiopia. Most of the studies were in vivo studies (25). Others include; clinical study (1), in vitro studies (2), and both in vivo and in vitro study (2). Trigonella foenum-graecum L., clinical study, showed an improved lipid profile in type II diabetic patients. Comparable blood sugar level (BSL) lowering effect to glibenclimide was observed with Persea Americana and Moringa stenopetala. Noteworthy in vitro half maximal inhibitory concentration (IC 50) of Aloe megalacantha $B$ and Aloe monticola $R$ were observed. Animal model studies demonstrated the relative safety of the plants extract and phytochemistry studies showed various components.

Conclusion: Medicinal plants used for management of diabetes mellitus in Ethiopia are worthy for further study for pharmacologically active ingredients and clinical evaluation.
\end{abstract}

Keywords: Medicinal plants, Hypoglycemic, a-Amylase, In vitro, In vivo, Ethiopia

\section{Background}

Diabetes mellitus (DM) is a metabolic disorder characterized by hyperglycemia due to impaired insulin secretion, defective insulin action or both. Chronic hyperglycemia is associated with long term microvascular complications affecting the cardiovascular, eyes, kidneys, and nerves [1]. The complications include

\footnotetext{
* Correspondence: dserawit@gmail.com; dserawit@std.must.ac.ug

'Pharm-BioTechnology and Traditional Medicine Center of Excellence (PHAR MBIOTRAC), Mbarara University of Science and Technology, P.O. Box 1410, Mbarara, Uganda

${ }^{2}$ School of Pharmacy, Faculty of Medicine, College of Medicine and Health Sciences, Hawassa University, P. O. Box 1560, Hawassa, Ethiopia

Full list of author information is available at the end of the article
}

nephropathy, retinopathy, nephropathy, peripheral vascular disease and coronary heart diseases [2]. The complications cause major impact on the lives and wellbeing of individuals, families and societies.

No successful cure for DM has yet been found but can be managed using insulin, diet modification and oral anti-diabetic agents. Herbal medicines could provide an alternative management. Compromised effectiveness, cost, accessibility, affordability, and tolerability are some of the limitations of current conventional anti-diabetic medicine. African medicinal plants are commonly used in the management of DM and provide an alternative therapy. Research is required on different indigenous plant and herbal formulations. The research will shed 
light on effectiveness and safety of herbal medicines. The findings will help to discover novel drugs and/or optimize the traditional use.

In Ethiopia, there are numerous medicinal plants used for DM and a number of these were assayed for their anti-diabetic activity. An estimated 80 to $90 \%$ of Ethiopians use herbal medicine as a primary form of health care [3] and many rural communities continue to depend on it [4]. There are preliminary studies on the scientific evidence of commonly used medicinal plants in Ethiopia though evidences were not synthesized. With a lack of critical appraisal on the currently evidence studies, this study aimed at reviewing information on the reported scientific evidence for effectiveness of medicinal plans used in Ethiopia in the management of DM.

\section{Methods 1}

\section{Study design}

This systematic review and meta-Analysis was conducted using databases searches and the reporting adhered to the Preferred Reporting Items for Systematic Review and Meta-Analysis [5]. PRISMA checklist was included as additional file (see Supplementary file 1).

\section{Search strategy}

Databases, PubMed, CINAHL, the Cochrane Central Register of Controlled Trials and clinical trial.gov and Google scholar, were searched from inception to May 25,2020 . The reference lists of all identified articles were searched for additional studies. Flow diagram was used to summarize the number of studies identified, screened, excluded and finally included in the study. Key words used in the search include (Diabetes mellitus OR T1DM OR type I diabetes mellitus OR T2DM OR type 2 diabetes mellitus) AND (Plant* OR herb* OR dietary supplement* OR traditional medicine*) AND (Ethiopia).

\section{Study selection and data extraction}

Three reviewers (SS, KE and EW) independently carried out a literature search and examined relevant studies and sequentially screened their titles and abstracts for eligibility. The full texts of potentially eligible studies were retrieved. Disagreements were resolved on discussion with the fourth author (SD). A screening guide was used to ensure that all review authors reliably apply the selection criteria. Human, animal and in-vitro studies which were conducted to examine anti-diabetic effect of medicinal plants in Ethiopia were included. Data extraction was performed using a pre-designed format. Extracted data include first author, study area, scientific, family and local name, study model used, the animal type used, extraction method used, a component of the extract used, duration of treatment, and change in BSL (from diabetic control, from normal control and standard control). A study is included if the effect on diabetic control is reported, otherwise it is excluded.

\section{Definition of terms}

Diabetic control refers animals with DM but no standard or experimental treatment is given which could refer a

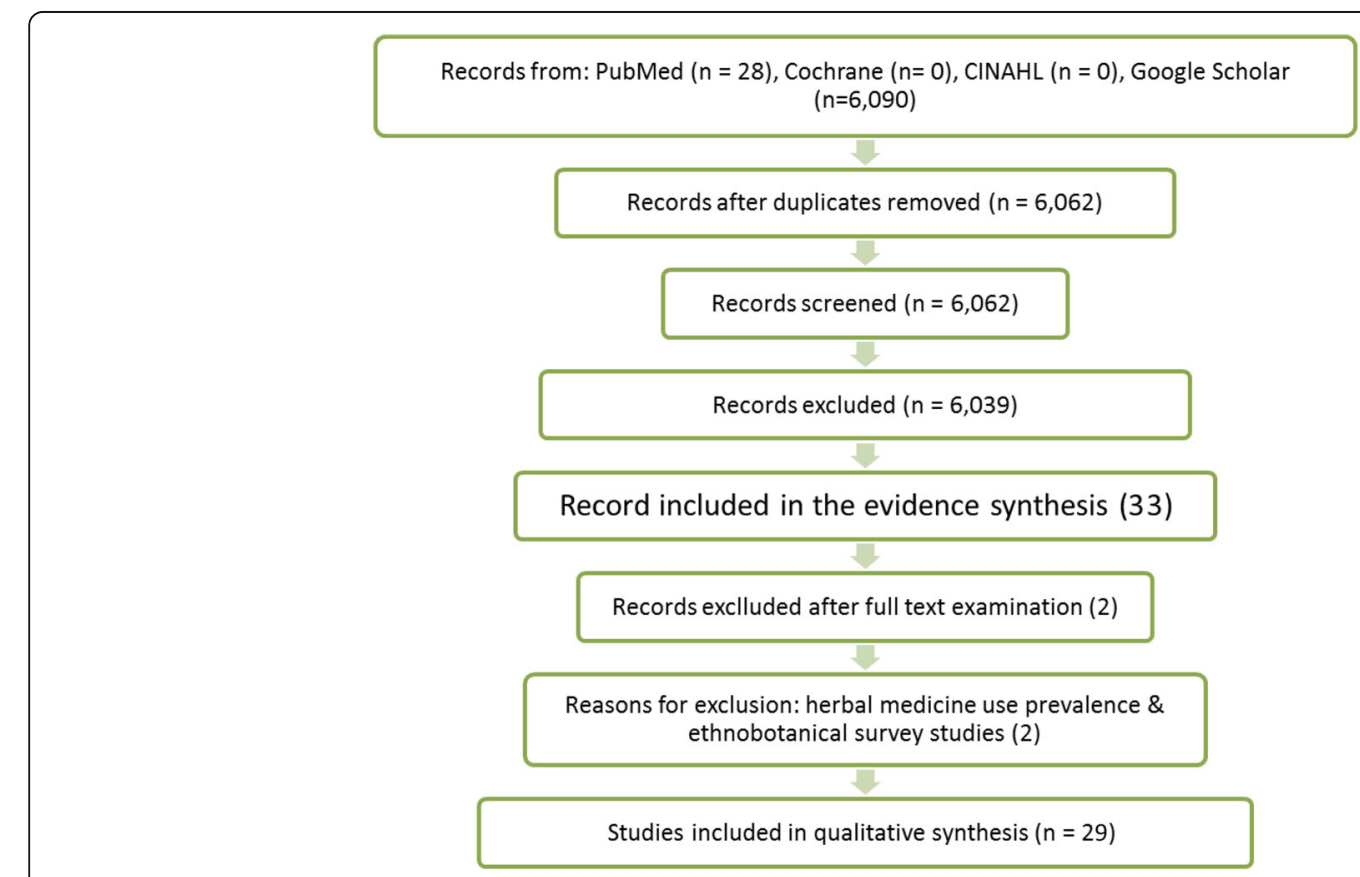

Fig. 1 Flow diagram showing, screened, excluded and included studies 
Table 1 Characteristics of included studies

\begin{tabular}{|c|c|c|c|c|}
\hline No & Study & Study area & Name of plant (Scientific, family, local) & Model \\
\hline 1. & Amare et al., 2020 [35] & Fiche, oromia region & Aloe pulcherrima Gilbert and Sebsebe (Aloaceae) & Male Swiss albino mice \\
\hline 2. & Alema et al., 2020 [10] & $\begin{array}{l}\text { Abiy Addi, Northwest } \\
\text { Tigray }\end{array}$ & Terminalia brownie Fresen, Combretaceae, Abaloweyba (Am) & in vitro and STZ-induced mice \\
\hline 3. & $\begin{array}{l}\text { Belayneh et al., } 2018 \\
\text { [22] }\end{array}$ & South Gondar zone & Calpurnia aurea, Fabaceae, digita (Am) & STZ-induced albino mice \\
\hline 4. & $\begin{array}{l}\text { Belayneh et al., } 2019 \\
\text { [12] }\end{array}$ & Gondar town & Datura stramonium L. solanaceae, atefaris (Am) & STZ-induced diabetic mice \\
\hline 5. & Birru et al., 2015 [21] & Lake Tana & Indigofera spicata Forssk, Fabaceae, yeayitmisir (Am) & $\begin{array}{l}\text { Alloxan-induced albino mice } \\
\text { \&wistar rats }\end{array}$ \\
\hline 6. & $\begin{array}{l}\text { Gebremeskel et al., } \\
2019[6]\end{array}$ & Mekelle & Trigonellafoenum-graecum, Fenugreek, Abish (Am) & T2DM \\
\hline 7. & $\begin{array}{l}\text { Hammeso et al., } 2019 \\
{[14]}\end{array}$ & SehartiSamre, Mekelle & Aloe megalacantha B, Aloaceae, Eret (Am) & STZ -induced mice \\
\hline 8. & $\begin{array}{l}\text { Kifle \& Eneyew, } 2020 \\
\text { [34] }\end{array}$ & South Gondar & Bersama abyssinica Fresen, tena adam (Am) & Male Swiss albino mice \\
\hline 9. & Kifle et al., 2020 [32] & South Gondar & Bersama abyssinica Fresen & Male Swiss albino mice \\
\hline 10. & $\begin{array}{l}\text { Makonnen et al., } 1997 \\
\text { [17] }\end{array}$ & Arbaminch area & $\begin{array}{l}\text { Moringa stenopetala, Moringaceae, shiferaw (Am), aleko } \\
\text { (Welaytegna) }\end{array}$ & Albino rabbits \\
\hline 11. & $\begin{array}{l}\text { Melaku and Amare } \\
\text { et al., } 2020[35]\end{array}$ & Wollo, Amhara region & Datura stramonium Linn (Solanaceae) & Male Swiss albino mice \\
\hline 12. & Mussa et al., 2008 [11] & Arba Minch & Moringas stenopetalla & Alloxan-induced mice \\
\hline 13. & Nardos, et al., 2011 [23] & Arbaminch town & $\begin{array}{l}\text { Moringa stenopetala, Moringaceae,Shiferaw (AM)/Haleko } \\
(\mathrm{GM})\end{array}$ & Alloxan-induced mice \\
\hline 14. & $\begin{array}{l}\text { Rao and Adinew } 2011 \\
\text { [33] }\end{array}$ & Tepi, & Persea Americana, Laurel, Avocado & STZ induced rats \\
\hline 15. & Seifu et al., 2017 [27] & Southern, Ethiopia & Melia azedarachlinn, Meliaceae, Laylak (milya) & Ob/obmice and Rats \\
\hline 16. & $\begin{array}{l}\text { Shewamene et al., } 2015 \\
\text { [16] }\end{array}$ & $\begin{array}{l}\text { Ayimba, Gondar, } \\
\text { Ethiopia }\end{array}$ & Otostegia integrifolia, Lamiaceae, Tunzut & STZinduced Rat or mice \\
\hline 17. & $\begin{array}{l}\text { Shewasinad et al., } 2019 \\
\text { [26] }\end{array}$ & Gudoberet, North Shoa & Thymus schimperi, Lamiaceae, Tosign & STZ induced mice \\
\hline 18. & Sileshi et al 2014 [7] & Arbaminch town & $\begin{array}{l}\text { Moringa Stenopetala,Moringaceae "Shiferaw (Am), Halekko } \\
\text { (Wolita/gammo)." }\end{array}$ & $\begin{array}{l}\text { Alloxan-induced Swiss albino } \\
\text { mice }\end{array}$ \\
\hline 19. & Tafesse, etal 2017 [20] & Addis Ababa & Ajuga remota, Lamiaceae, Akorarach & Alloxan-induced mice \\
\hline 20. & Tamiru et al. 2012 [28] & $\begin{array}{l}\text { Dirre, way from } \\
\text { Bishoftu to Ziquala }\end{array}$ & Caylusea abyssinica (fresen.) fisch. \&Mey. Resedaceae & $\begin{array}{l}\text { STZ induced Swiss albino mice } \\
\text { and Wistar rats }\end{array}$ \\
\hline 21. & Taye et al., 2020 [29] & Suluta, Oromia Region & Thymus schimperi (Lamiaceae) & Swiss albino mice \\
\hline 22. & Tefera et al., 2020 [30] & Woreta, Amhara region & L. culinaris & Swiss albino mice \\
\hline 23. & Tekulu et al. 2019 [25] & Tigray & $\begin{array}{l}\text { Aloe megalacantha B.,Asphodelaceae, Aloe monticola R., } \\
\text { Asphodelaceae"yedega ret. (Am)" }\end{array}$ & in vitro \\
\hline 24. & Tesfaye et al., 2016 [13] & Wolayta soddo, SNNPR & Justicia Schimperia naacanthaceae" Sensel or Simiza" & Normal andSTZ-induced mice \\
\hline 25. & Toma et al., 2012 [19] & Wolaitta zone, SNNPR & $\begin{array}{l}\text { Moringa Stenopetala, Moringaceae "shiferaw Am" } \\
\text { "HalekkoWo." }\end{array}$ & Alloxan Induced mice \\
\hline 26. & Toma et al., 2014 [8] & $\begin{array}{l}\text { GamoGofa Zone, SNNP } \\
\text { R }\end{array}$ & Moringa Stenopetala, & in vitro \\
\hline 27. & Toma et al., 2015 [9] & $\begin{array}{l}\text { GamoGofa Zone, SNNP } \\
\text { R }\end{array}$ & Moringa Stenopetala & STZ-induced rats \\
\hline 28. & Tsegaye et al., 2008 [18] & $\begin{array}{l}\text { Semen Mazegaja, Addis } \\
\text { Ababa }\end{array}$ & UrticasimensisHochst. ex. A. Rich, "Samma" & STZ-induced mice \\
\hline 29. & Yibru et al., 2015 [15] & Addis Ababa & Coriandrum sativum, "dembellal" & STZ-induced mice \\
\hline
\end{tabular}


Table $\mathbf{2}$ In vitro anti-diabetic activity of medicinal plants in Ethiopia

\begin{tabular}{|c|c|c|c|c|c|c|}
\hline Study & Scientific name & $\begin{array}{l}\text { Parts } \\
\text { used }\end{array}$ & Extraction method & Assay method & $\begin{array}{l}\text { Active cpd, Fraction / } \\
\text { extraction }\end{array}$ & IC50 \\
\hline \multirow[t]{6}{*}{ Alema et al. 2020 [10] } & Terminalia brownii Fresen & stem bark & $\begin{array}{l}\text { methanolic extract \& } \\
\text { solvent fractions }\end{array}$ & $\begin{array}{l}\text { a-Amylase Inhibition } \\
\text { (chromogenic DNSA method) }\end{array}$ & aqueous fraction & $\begin{array}{l}>100 \mu \mathrm{g} / \\
\mathrm{ml}\end{array}$ \\
\hline & & & & & Butanol fraction & $\begin{array}{l}84.69 \mu \mathrm{g} / \\
\mathrm{ml}\end{array}$ \\
\hline & & & & & chloroform fraction & $\begin{array}{l}63.41 \mu \mathrm{g} / \\
\mathrm{ml}\end{array}$ \\
\hline & & & & & ethyl acetate fraction & $\begin{array}{l}>100 \mu \mathrm{g} / \\
\mathrm{ml}\end{array}$ \\
\hline & & & & & crude extract & $\begin{array}{l}>100 \mu \mathrm{g} / \\
\mathrm{ml}\end{array}$ \\
\hline & & & & & Acarbose & $\begin{array}{l}\sim 12.5 \mu \mathrm{g} / \\
\mathrm{ml}\end{array}$ \\
\hline \multirow[t]{5}{*}{ Kifle and Eneyew., 2020 [34] } & Bersama abyssinica & leaf & Methanolic Extraction & $\begin{array}{l}\text { a-Amylase Inhibition } \\
\text { (chromogenic DNSA method) }\end{array}$ & Chloroform fraction & $\begin{array}{l}30.97+ \\
0.84\end{array}$ \\
\hline & & & & & Ethyl acetate fraction & $\begin{array}{l}20.34+ \\
0.67\end{array}$ \\
\hline & & & & & Aqueous fraction & $\begin{array}{l}13.33+ \\
0.57\end{array}$ \\
\hline & & & & & Crude extract & $6.57+0.74$ \\
\hline & & & & & Acarbose & $2.26+0.53$ \\
\hline \multirow[t]{5}{*}{ Toma et al. 2014 [8] } & Moringa Stenopetala & powdered & ethanol extract & Pancreatic a-amylase & ethanol extract & $>5 \mathrm{mg} / \mathrm{ml}$ \\
\hline & & leaves & & Maltase & & $>5 \mathrm{mg} / \mathrm{ml}$ \\
\hline & & & & Pancreatic C. esterase & & $>5 \mathrm{mg} / \mathrm{ml}$ \\
\hline & & & & Pancreatic lipase & & $>5 \mathrm{mg} / \mathrm{ml}$ \\
\hline & & & & Sucrase & & $\begin{array}{l}1.47 \pm 0.19 \\
\mathrm{mg} / \mathrm{ml}\end{array}$ \\
\hline \multirow[t]{7}{*}{ Tekulu et al. 2019 [25] } & $\begin{array}{l}\text { Aloe megalacantha } B \\
\text { Aloe monticola } R\end{array}$ & leaf & Methanol extract & $\begin{array}{l}\text { a-Amylase Inhibition } \\
\text { (chromogenic DNSA method) }\end{array}$ & $\begin{array}{l}\text { TLC fraction from A. } \\
\text { megalacantha coded as AM1 }\end{array}$ & $\begin{array}{l}37.83 \pm \\
3.31 \mu \mathrm{g} / \mathrm{mL}\end{array}$ \\
\hline & & & & & Leaf latex ofA. megalacantha & $\begin{array}{l}74.76 \pm \\
1.98 \mu \mathrm{g} / \mathrm{mL}\end{array}$ \\
\hline & & & & & $\begin{array}{l}\text { TLC fraction from A. } \\
\text { megalacantha coded as AM2 }\end{array}$ & $\begin{array}{l}96.75 \pm \\
1.98 \mu \mathrm{g} / \mathrm{mL}\end{array}$ \\
\hline & & & & & Leaf latex ofA. monticola & $\begin{array}{l}78.10 \pm \\
1.88 \mu \mathrm{g} / \mathrm{mL}\end{array}$ \\
\hline & & & & & $\begin{array}{l}\text { TLC fraction from A. } \\
\text { monticola, AG1 }\end{array}$ & $\begin{array}{l}56.95 \pm \\
1.88 \mu \mathrm{g} / \mathrm{mL}\end{array}$ \\
\hline & & & & & $\begin{array}{l}\text { TLC fraction from A. } \\
\text { monticola, AG2 }\end{array}$ & $\begin{array}{l}64.03 \pm \\
3.60 \mu \mathrm{g} / \mathrm{mL}\end{array}$ \\
\hline & & & & & Acarbose & $\begin{array}{l}16.49 \pm \\
1.91 \mu \mathrm{g} / \mathrm{mL}\end{array}$ \\
\hline
\end{tabular}

placebo control. Whereas standard controls are animals with induced DM and treated with standard treatment most commonly glibenclamide. Normal controls are animal being followed and managed in the same was as experimental conduction but no induction of $\mathrm{Dm}$ or treatment is given.

\section{Results}

\section{Characteristics of included studies}

A total of 17,954 articles were identified through the electronic database search. De-duplication reduced the total number of articles to 6, 090. After titles and abstracts screening, 33 articles remained and further screening left 29 articles for inclusion [6-28],
Fig 1. Among the studies twenty-four were in vivo studies [7, 9, 11-24, 26-32, 33], two were in vitro studies $[8,25]$ and three was both in vivo and in vitro study $[10,34,35]$. Reasons for exclusion include: herbal medicine use prevalence and ethnobotanical survey studies [36, 37]. Ten of the total studies were conducted in the southern nation nationalities region, 9 in Amhara, four in Tigra, 3 in Addis Abab, 3 in Oromia. Seven studies were done in Moringa Stenopetala [7-9, 11, 17, 19, 23], 2 in Aloe megalacantha B [14, 25], 2 in Bersama abyssinica Fresen [32, 34], 2 in Datura stramonium [12, 31], 2 in Thymus schimperi [26, 29], and 14 in different plants. 
Table 3 In vivo anti-diabetic activity of medicinal plat in Ethiopia

\begin{tabular}{lll}
\hline Study & Plant & Animal type \\
\hline $\begin{array}{l}\text { Amare et al., } \\
2020[35]\end{array}$ & Terminalia brownii Fresen & Normoglycemic Mice \\
& & $\begin{array}{l}\text { Mice Loaded with Oral } \\
\text { Glucose }\end{array}$ \\
& STZ -induced Mice
\end{tabular}

Alema et al,, $2020[10]$

(20)

Belayneh et al., Calpurnia aurea 2018 [22]

Belaynehet al 2019 [12]

Birru

[21]

Glucose

STZ -induced Mice Loaded with Oral Glucose

STZ -induced Mice

Diabetic mice

\begin{tabular}{llll}
$\begin{array}{l}\text { Extraction } \\
\text { method/ } \\
\text { component }\end{array}$ & $\begin{array}{l}\text { Duration } \\
\text { of } \\
\text { treatment }\end{array}$ & $\begin{array}{l}\text { From diabetic } \\
\text { Control }\end{array}$ & From standard control \\
\hline
\end{tabular}

$200 \mathrm{mg} / \mathrm{kg}=16.74+2.57$

$400 \mathrm{mg} / \mathrm{kg}=6.9 \pm 2.33$

$600 \mathrm{mg} / \mathrm{kg}=5.36 \pm 2.20$

$200 \mathrm{mg} / \mathrm{kg}=16.30 \pm 1.11$

$400 \mathrm{mg} / \mathrm{kg}=7.14 \pm 0.46$

$600 \mathrm{mg} / \mathrm{kg}=3.25 \pm 0.96$

$200 \mathrm{mg} / \mathrm{kg}=-22.48 \pm \quad 200 \mathrm{mg} / \mathrm{kg}=7.94 \pm 2.72$

$4.66 \quad 400 \mathrm{mg} / \mathrm{kg}=3.82 \pm 4.51$

$400 \mathrm{mg} / \mathrm{kg}=-26.6 \pm \quad 600 \mathrm{mg} / \mathrm{kg}=0.88 \pm 2.02$

5.89

$600 \mathrm{mg} / \mathrm{kg}=-29.54 \pm$

4.29

Methanolic E. 15 days

$-$

$50 \mathrm{mg} / \mathrm{kg}=-43.5 \pm 6.21500 \mathrm{mg} / \mathrm{kg}=$

$-41 \pm 7.12$

$750 \mathrm{mg} / \mathrm{kg}=-32.5 \pm 9.37$

Mice Loaded with Oral Methanolic E.

$-$

$250 \mathrm{mg} / \mathrm{kg}=-40 \pm 7.3$

$500 \mathrm{mg} / \mathrm{kg}=-46.5 \pm 7.67$

$750 \mathrm{mg} / \mathrm{kg}=-44.67 \pm 8.38$

Methanolic E.

$250 \mathrm{mg} / \mathrm{kg}=151.5 \pm$

$250 \mathrm{mg} / \mathrm{kg}=-123.67 \pm 43.02$

$250 \mathrm{mg}$

$500 \mathrm{mg} / \mathrm{kg}=-78.67 \pm 46.61$

$500 \mathrm{mg} / \mathrm{kg}=196.5 \pm \quad 750 \mathrm{mg} / \mathrm{kg}=-11.5 \pm 34.84$

6186

$750 \mathrm{mg} / \mathrm{kg}=264.33 \pm$

53.5

aqueous $\mathrm{F}$.

$500 \mathrm{mg} / \mathrm{kg}=324.84 \pm$ 40.14

Ethyl acetate $\mathrm{F}$.

$500 \mathrm{mg} / \mathrm{kg}=278.5 \pm$ 51.65

Butanol F.

$500 \mathrm{mg} / \mathrm{kg}=68.67 \pm$ 62.71

Normoglycemic Mice Methanol E 14 Days

Ethanol E 14 days

$100 \mathrm{mg} / \mathrm{kg}=4.06 \pm$ 8.88

$200 \mathrm{mg} / \mathrm{kg}=11.73 \pm$

9.38

$400 \mathrm{mg} / \mathrm{kg}=0.67 \pm$

10.36

$100 \mathrm{mg} / \mathrm{kg}=28.12 \pm$

14.9

$200 \mathrm{mg} / \mathrm{kg}=18.95 \pm$

14.5

$400 \mathrm{mg} / \mathrm{kg}=30.51 \pm$

13.93

$100 \mathrm{mg} / \mathrm{kg}=144.94 \pm$ 52.94

$200 \mathrm{mg} / \mathrm{kg}=153.11 \pm$

60.64

$400 \mathrm{mg} / \mathrm{kg}=134.89 \pm$

23.25

$100 \mathrm{mg} / \mathrm{kg}=16.72 \pm$
7.87
$200 \mathrm{mg} / \mathrm{kg}=$
$20.11 \pm 5.76$
$400 \mathrm{mg} / \mathrm{kg}=15.39 \pm$
5.30
$100 \mathrm{mg} / \mathrm{kg}=38.12 \pm$
11.30
$200 \mathrm{mg} / \mathrm{kg}=38.62 \pm$
11.25
$400 \mathrm{mg} / \mathrm{kg}=$
$42.89 \pm 11.35$

$100 \mathrm{mg} / \mathrm{kg}=-$

$6.66 \pm 7.67$

$200 \mathrm{mg} / \mathrm{kg}=10.48 \pm$

7.11

$400 \mathrm{mg} / \mathrm{kg}=-$

$2.5 \pm 6.45$
$100 \mathrm{mg} / \mathrm{kg}=-22.55 \pm 11.04$

$200 \mathrm{mg} / \mathrm{kg}=-31.72+10.47$

$400 \mathrm{mg} / \mathrm{kg}=-20.16 \pm 9.55$

$100 \mathrm{mg} / \mathrm{kg}=-98.95 \pm 50.04$

$200 \mathrm{mg} / \mathrm{kg}=-90.78 \pm 58.12$

$400 \mathrm{mg} / \mathrm{kg}=-109+58.48$

$100 \mathrm{mg} / \mathrm{kg}=-23.39 \pm 8.10$

$200 \mathrm{mg} / \mathrm{kg}=-20 \pm 6.08$

$400 \mathrm{mg} / \mathrm{kg}=-24.72 \pm 5.66$

$100 \mathrm{mg} / \mathrm{kg}=-23.71 \pm 2.75$

$200 \mathrm{mg} / \mathrm{kg}=-23.27 \pm 2.51$

$400 \mathrm{mg} / \mathrm{kg}=-19 \pm 5.30$

$100 \mathrm{mg} / \mathrm{kg}=-17 \pm 6.85$

$200 \mathrm{mg} / \mathrm{kg}=0.5 \pm 6.22$

$400 \mathrm{mg} / \mathrm{kg}=-12.48 \pm 5.51$ 
Table 3 In vivo anti-diabetic activity of medicinal plat in Ethiopia (Continued)

\begin{tabular}{|c|c|c|c|c|c|c|}
\hline Study & Plant & Animal type & $\begin{array}{l}\text { Extraction } \\
\text { method/ } \\
\text { component }\end{array}$ & $\begin{array}{l}\text { Duration } \\
\text { of } \\
\text { treatment }\end{array}$ & $\begin{array}{l}\text { From diabetic } \\
\text { Control }\end{array}$ & From standard control \\
\hline & & $\begin{array}{l}\text { Normoglycemic rat } \\
\text { Loaded with Oral } \\
\text { Glucose }\end{array}$ & & & $\begin{array}{l}100 \mathrm{mg} / \mathrm{kg}=3.17 \pm \\
10.08 \\
200 \mathrm{mg} / \mathrm{kg}=5.5 \pm 8.17 \\
400 \mathrm{mg} / \mathrm{kg}=10.17 \pm \\
6.73\end{array}$ & $\begin{array}{l}100 \mathrm{mg} / \mathrm{kg}=-26.67 \pm 10.22 \\
200 \mathrm{mg} / \mathrm{kg}=-24.83 \pm 8.33 \\
400 \mathrm{mg} / \mathrm{kg}=-20.17 \pm 6.93\end{array}$ \\
\hline & & alloxan induced mice & & & $\begin{array}{l}100 \mathrm{mg} / \mathrm{kg}=179.67 \pm \\
30.71 \\
200 \mathrm{mg} / \mathrm{kg}= \\
196 \pm 26.86 \\
400 \mathrm{mg} / \mathrm{kg}= \\
196.67 \pm 24.73\end{array}$ & $\begin{array}{l}100 \mathrm{mg} / \mathrm{kg}=-30.33 \pm 23.22 \\
200 \mathrm{mg} / \mathrm{kg}=-14 \pm 17.80 \\
400 \mathrm{mg} / \mathrm{kg}=-13.33 \pm 14.41\end{array}$ \\
\hline \multirow[t]{3}{*}{$\begin{array}{l}\text { Hammeso, et al., } \\
2019[14]\end{array}$} & Aloe megalacantha B. & Normoglycemic mice & Aqueous $\mathrm{E}$ & 14 days & $\begin{array}{l}100 \mathrm{mg} / \mathrm{kg}=55.53 \pm \\
12.65 \\
200 \mathrm{mg} / \mathrm{kg}=55.66 \pm \\
13.98 \\
400 \mathrm{mg} / \mathrm{kg}=57.61 \pm \\
13.32\end{array}$ & $\begin{array}{l}100 \mathrm{mg} / \mathrm{kg}=-20.16 \pm 8.18 \\
200 \mathrm{mg} / \mathrm{kg}=-20 \pm 10.13 \\
400 \mathrm{mg} / \mathrm{kg}=-18.05 \pm 9.19\end{array}$ \\
\hline & & $\begin{array}{l}\text { Postprandial } \\
\text { Normoglycemic mice }\end{array}$ & & & $\begin{array}{l}100 \mathrm{mg} / \mathrm{kg}=32.05 \pm \\
8.49 \\
200 \mathrm{mg} / \mathrm{kg}=39.83 \pm \\
5.60 \\
400 \mathrm{mg} / \mathrm{kg}=30.83 \pm \\
5.54\end{array}$ & $\begin{array}{l}100 \mathrm{mg} / \mathrm{kg}=-8.11 \pm 8.07 \\
200 \mathrm{mg} / \mathrm{kg}=-0.33 \pm 4.94 \\
400 \mathrm{mg} / \mathrm{kg}=-9.33 \pm 4.87\end{array}$ \\
\hline & & $\begin{array}{l}\text { STZ-induced diabetic } \\
\text { mice }\end{array}$ & & & $\begin{array}{l}100 \mathrm{mg} / \mathrm{kg}=65 \pm 5.57 \\
200 \mathrm{mg} / \mathrm{kg}=64.83 \pm \\
5.42 \\
400 \mathrm{mg} / \mathrm{kg}=66.83 \pm \\
5.39\end{array}$ & $\begin{array}{l}100 \mathrm{mg} / \mathrm{kg}=-12.16 \pm 2.83 \\
200 \mathrm{mg} / \mathrm{kg}=-12.33 \pm 2.52 \\
400 \mathrm{mg} / \mathrm{kg}=-10.33 \pm 2.46\end{array}$ \\
\hline \multirow[t]{6}{*}{$\begin{array}{l}\text { Kifle and } \\
\text { Eneyew., } \\
2020[34]\end{array}$} & $\begin{array}{l}\text { Bersama abyssinica } \\
\text { Fresen }\end{array}$ & Normoglycemic Mice & Methanolic E. & $8 \mathrm{~h}$ & & $\begin{array}{l}100 \mathrm{mg} / \mathrm{kg}=25.67 \pm 3.07 \\
200 \mathrm{mg} / \mathrm{kg}=14.17 \pm 2.39 \\
400 \mathrm{mg} / \mathrm{kg}=8.83 \pm 3.43\end{array}$ \\
\hline & & $\begin{array}{l}\text { Mice Loaded with Oral } \\
\text { Glucose }\end{array}$ & & & & $\begin{array}{l}100 \mathrm{mg} / \mathrm{kg}=14.34 \pm 10.30 \\
200 \mathrm{mg} / \mathrm{kg}=10.17 \pm 6.38 \\
400 \mathrm{mg} / \mathrm{kg}=2.50 \pm 2.65\end{array}$ \\
\hline & & STZ -induced Diabetic & Methanolic E. & & & $400 \mathrm{mg} / \mathrm{kg}=21.17 \pm 12.47$ \\
\hline & & & chloroform $\mathrm{F}$. & & & $400 \mathrm{mg} / \mathrm{kg}=104.0 \pm 11.07$ \\
\hline & & & Ethyl acetate $F$. & & & $400 \mathrm{mg} / \mathrm{kg}=69.67 \pm 15.32$ \\
\hline & & & aqueous $\mathrm{F}$. & & & $400 \mathrm{mg} / \mathrm{kg}=54.5 \pm 9.51$ \\
\hline \multirow[t]{5}{*}{$\begin{array}{l}\text { Kifle, et al., } 2020 \\
\text { [32] }\end{array}$} & Abyssinica Fresen. & Normoglycemic mice & Aqueous $F$ & 14 days & & $\begin{array}{l}100 \mathrm{mg} / \mathrm{kg}=26.67 \pm 2.28 \\
200 \mathrm{mg} / \mathrm{kg}=15.17 \pm 2.72 \\
400 \mathrm{mg} / \mathrm{kg}=11.5 \pm 5.47\end{array}$ \\
\hline & & & Ethyl acetate F & & & $\begin{array}{l}100 \mathrm{mg} / \mathrm{kg}=29.5 \pm 6.28 \\
200 \mathrm{mg} / \mathrm{kg}=18.00 \pm 3.13 \\
400 \mathrm{mg} / \mathrm{kg}=16.33 \pm 2.31\end{array}$ \\
\hline & & $\begin{array}{l}\text { Mice Loaded with Oral } \\
\text { Glucose }\end{array}$ & Aqueous F & & & $\begin{array}{l}100 \mathrm{mg} / \mathrm{kg}=21.5 \pm 6.24 \\
200 \mathrm{mg} / \mathrm{kg}=13.67 \pm 6.11 \\
400 \mathrm{mg} / \mathrm{kg}=5.67 \pm 6.67\end{array}$ \\
\hline & & & Ethyl acetate $\mathrm{F}$ & & & $\begin{array}{l}100 \mathrm{mg} / \mathrm{kg}=19.5 \pm 7.33 \\
200 \mathrm{mg} / \mathrm{kg}=14.67 \pm 6.83 \\
400 \mathrm{mg} / \mathrm{kg}=9.5 \pm 6.31\end{array}$ \\
\hline & & STZ-induced mice & Aqueous F & & $\begin{array}{l}100 \mathrm{mg} / \mathrm{kg}=-119.5 \pm \\
14.22 \\
200 \mathrm{mg} / \mathrm{kg}=- \\
142.83 \pm 16.98 \\
400 \mathrm{mg} / \mathrm{kg}=-180.0 \pm \\
12.56\end{array}$ & $\begin{array}{l}100 \mathrm{mg} / \mathrm{kg}=95.33 \pm 11.82 \\
200 \mathrm{mg} / \mathrm{kg}=72.0 \pm 15.02 \\
400 \mathrm{mg} / \mathrm{kg}=34.83 \pm 9.75\end{array}$ \\
\hline $\begin{array}{l}\text { Makonnenet al., } \\
1997[17]\end{array}$ & Moringa stenopetala, & Albino rabbits & Aqueous $\mathrm{E}$ & $6 \mathrm{~h}$ & $\begin{array}{l}10 \mathrm{~g} / \mathrm{kg}=5.5 \pm 1.48 \\
15 \mathrm{~g} / \mathrm{kg}=9.8 \pm 1.04\end{array}$ & $\begin{array}{l}10 \mathrm{~g} / \mathrm{kg}=-37.7 \pm 1.4815 \mathrm{~g} / \mathrm{kg}=- \\
33.4 \pm 1.04\end{array}$ \\
\hline \multirow[t]{2}{*}{$\begin{array}{l}\text { Melaku and } \\
\text { Amare et al., } \\
2020[35]\end{array}$} & Datura stramonium Linn & Normoglycemic mice & Methanolic E & 14 days & & $\begin{array}{l}100 \mathrm{mg} / \mathrm{kg}=17.64 \pm 2.13 \\
200 \mathrm{mg} / \mathrm{kg}=17.11 \pm 2.91 \\
400 \mathrm{mg} / \mathrm{kg}=15.66 \pm 3.40\end{array}$ \\
\hline & & Diabetic Mice & & & & $\begin{array}{l}100 \mathrm{mg} / \mathrm{kg}=10.04 \pm 1.66 \\
200 \mathrm{mg} / \mathrm{kg}=8.37 \pm 1.94 \\
400 \mathrm{mg} / \mathrm{kg}=6.99 \pm 1.65\end{array}$ \\
\hline
\end{tabular}


Table 3 In vivo anti-diabetic activity of medicinal plat in Ethiopia (Continued)

\begin{tabular}{|c|c|c|c|c|c|c|}
\hline Study & Plant & Animal type & $\begin{array}{l}\text { Extraction } \\
\text { method// } \\
\text { component }\end{array}$ & $\begin{array}{l}\text { Duration } \\
\text { of } \\
\text { treatment }\end{array}$ & $\begin{array}{l}\text { From diabetic } \\
\text { Control }\end{array}$ & From standard control \\
\hline \multirow{8}{*}{$\begin{array}{l}\text { Mussa. et al., } \\
2008 \text { [11] }\end{array}$} & \multirow[t]{8}{*}{ Moringa stenopetalla, } & \multirow[t]{4}{*}{ Non-diabetic Mice } & Aqueous E. & \multirow[t]{8}{*}{$6 \mathrm{~h}$} & $20.10 \pm 10.02$ & $-23.60 \pm 8.13$ \\
\hline & & & Chloroform F. & & $21.50 \pm 10.70$ & $-22.20 \pm 8.96$ \\
\hline & & & Butanol F. & & $15.50 \pm 8.39$ & $-28.20 \pm 5.98$ \\
\hline & & & Aqueous R. & & $12.50 \pm 10.38$ & $-31.20 \pm 8.58$ \\
\hline & & \multirow[t]{4}{*}{ Alloxan-induced mice } & Aqueous E. & & $12.60 \pm 10.16$ & $-44.70 \pm 9.24$ \\
\hline & & & Chloroform F. & & $16.00 \pm 7.71$ & $-41.30 \pm 6.44$ \\
\hline & & & Butanol F. & & $41.40 \pm 10.56$ & $-15.90 \pm 9.67$ \\
\hline & & & Aqueous R. & & $37.80 \pm 7.29$ & $-19.50 \pm 5.94$ \\
\hline \multirow{16}{*}{$\begin{array}{l}\text { Nardos, et al., } \\
2011[23]\end{array}$} & \multirow[t]{16}{*}{ Moringa stenopetala } & \multirow{4}{*}{$\begin{array}{l}\text { Alloxan-induced } \\
\text { diabetic mice } \\
\text { (Repeated doses) }\end{array}$} & Aqueous E & \multirow[t]{16}{*}{8 days } & $55.4 \pm 4.55$ & $-8.6 \pm 4.78$ \\
\hline & & & Ethanol E & & $59.2 \pm 3.26$ & $-4.8 \pm 3.58$ \\
\hline & & & Chloroform F & & $47.9 \pm 2.26$ & $-16.1 \pm 2.70$ \\
\hline & & & Butanol F & & $46 \pm 3.53$ & $-18 \pm 3.82$ \\
\hline & & \multirow{6}{*}{$\begin{array}{l}\text { Normoglycemic mice } \\
\text { (Effects of a single } \\
\text { dose) }\end{array}$} & Aqueous $\mathrm{E}$ & & $23.2 \pm 7.53$ & $-14.8 \pm 5.50$ \\
\hline & & & Ethanol E & & $24.8 \pm 8.8$ & $-13.2 \pm 7.14$ \\
\hline & & & Petroleum F & & $2.2 \pm 7.49$ & $-35.8 \pm 5.46$ \\
\hline & & & Chloroform F & & $20.6 \pm 7.75$ & $-17.4 \pm 5.79$ \\
\hline & & & Butanol F & & $24.4 \pm 7.78$ & $-13.6 \pm 5.85$ \\
\hline & & & Aqueous R & & $13.2 \pm 7.83$ & $-24.6 \pm 5.90$ \\
\hline & & \multirow{6}{*}{$\begin{array}{l}\text { Alloxan induced mice } \\
\text { (single dose) }\end{array}$} & Aqueous E & & $50.8 \pm 4.48$ & $-27.4 \pm 4.3$ \\
\hline & & & Ethanol E & & $54.2 \pm 6.08$ & $-24 \pm 5.95$ \\
\hline & & & Petroleum F & & $5.2 \pm 3.44$ & $-73 \pm 3.20$ \\
\hline & & & Chloroform F & & $59.2 \pm 6.26$ & $-19 \pm 6.13$ \\
\hline & & & Butanol F & & $55.2 \pm 4.10$ & $-23 \pm 3.90$ \\
\hline & & & Aqueous R & & $18.8 \pm 3.33$ & $-59.4 \pm 3.08$ \\
\hline $\begin{array}{l}\text { Rao and Adinew } \\
2011 \text { [33] }\end{array}$ & Persea Americaca & STZ-induced rats & Ethanol E & 30 days & $145.18 \pm 18.89$ & $-6.84 \pm 7.14$ \\
\hline $\begin{array}{l}\text { Seifu, et al., } 2017 \\
\text { [27] }\end{array}$ & Melia azedarach Lin, & $\mathrm{Ob} / \mathrm{ob}$ mice and rat & Aqueous E & 20 days & $\begin{array}{l}\text { Decreased at 200mgg/ } \\
\mathrm{kg} \text { and } 400 \mathrm{mg} / \mathrm{kg}\end{array}$ & Similar at $200 \mathrm{mgg} / \mathrm{kg}$ and $400 \mathrm{mg} / \mathrm{kg}$ \\
\hline \multirow[t]{3}{*}{$\begin{array}{l}\text { Shewamene, } \\
\text { et al., } 2015 \text { [16] }\end{array}$} & \multirow[t]{3}{*}{ Otostegiainte grifolia, } & Normoglycemic mice & Methanol E & $4 \mathrm{~h}$ & $\begin{array}{l}\text { At } 100 \mathrm{mg} / \mathrm{kg}= \\
25.61 \pm 5.76 \\
\text { At } 200 \mathrm{mg} / \mathrm{kg}= \\
33.77 \pm 4.44 \\
\text { At } 400 \mathrm{mg} / \mathrm{kg}=1.48 \pm \\
7.03\end{array}$ & $\begin{array}{l}100 \mathrm{mg} / \mathrm{kg}=-9.16 \pm 4.18 \\
200 \mathrm{mg} / \mathrm{kg}=-1.00 \pm 2.06 \\
400 \mathrm{mg} / \mathrm{kg}=-36.25 \pm 5.81\end{array}$ \\
\hline & & $\begin{array}{l}\text { Streptozotocin induced } \\
\text { mice }\end{array}$ & Methanol E & & $\begin{array}{l}100 \mathrm{mg} / \mathrm{kg}=183.67 \pm \\
51.36 \\
200 \mathrm{mg} / \mathrm{kg}=215.67 \pm \\
74.96 \\
400 \mathrm{mg} / \mathrm{kg}=168 \pm \\
50.20\end{array}$ & $\begin{array}{l}100 \mathrm{mg} / \mathrm{kg}=-52.45 \pm 47.08 \\
200 \mathrm{mg} / \mathrm{kg}=-20.45 \pm 71 \\
400 \mathrm{mg} / \mathrm{kg}=-67.62 \pm 45.84\end{array}$ \\
\hline & & $\begin{array}{l}\text { Oral Glucose Tolerance } \\
\text { Test in rats }\end{array}$ & Methanol E & $4 \mathrm{~h}$ & $\begin{array}{l}100 \mathrm{mg} / \mathrm{kg}=33.39 \pm \\
5.02 \\
200 \mathrm{mg} / \mathrm{dl}=50.39 \pm \\
4.37 \\
400 \mathrm{mg} / \mathrm{kg}=-22.19 \pm \\
15.82\end{array}$ & $\begin{array}{l}100 \mathrm{mg} / \mathrm{kg}=-40.11 \pm 6.64 \\
200 \mathrm{mg} / \mathrm{kg}=-23.11 \pm 3.93 \\
400 \mathrm{mg} / \mathrm{kg}=-95.69 \pm 15.71\end{array}$ \\
\hline \multirow[t]{2}{*}{$\begin{array}{l}\text { Shewasinad, } \\
\text { et al., } 2019 \text { [26] }\end{array}$} & \multirow[t]{2}{*}{ Thymus schimperi } & $\begin{array}{l}\text { Normoglycemic mice } \\
\text { or rat }\end{array}$ & Methanol E & Day 15 & $\begin{array}{l}250 \mathrm{mg} / \mathrm{kg}=-11.8 \pm \\
8.93 \\
500 \mathrm{mg} / \mathrm{kg}=-19.6 \pm \\
7.49750 \mathrm{mg} / \mathrm{kg}=1.6 \pm \\
8.48\end{array}$ & $\begin{array}{l}250 \mathrm{mg} / \mathrm{kg}=-75.0 \pm 7.16 \\
500 \mathrm{mg} / \mathrm{kg}=-82.8 \pm 5.26 \\
750 \mathrm{mg} / \mathrm{kg}=-61.6 \pm 6.60\end{array}$ \\
\hline & & $\begin{array}{l}\text { Streptozotocin induced } \\
\text { rat or mice }\end{array}$ & Methanol E & Day 15 & $\begin{array}{l}250 \mathrm{mg} / \mathrm{kg}=109.83 \pm \\
11.42 \\
500 \mathrm{mg} / \mathrm{kg}=125.27 \pm \\
51.21 \\
750 \mathrm{mg} / \mathrm{kg}=146.17 \pm\end{array}$ & $\begin{array}{l}250 \mathrm{mg} / \mathrm{kg}=-112.84 \pm 35.52 \\
500 \mathrm{mg} / \mathrm{kg}=-97.4 \pm 50.81 \\
750 \mathrm{mg} / \mathrm{kg}=-76.5 \pm 45.08\end{array}$ \\
\hline
\end{tabular}


Table 3 In vivo anti-diabetic activity of medicinal plat in Ethiopia (Continued)

\begin{tabular}{|c|c|c|c|c|c|c|}
\hline Study & Plant & Animal type & $\begin{array}{l}\text { Extraction } \\
\text { method/ } \\
\text { component }\end{array}$ & $\begin{array}{l}\text { Duration } \\
\text { of } \\
\text { treatment }\end{array}$ & $\begin{array}{l}\text { From diabetic } \\
\text { Control }\end{array}$ & From standard control \\
\hline & & & & & 45.45 & \\
\hline & & & Ethyl acetate $\mathrm{F}$ & Day 15 & $\begin{array}{l}250 \mathrm{mg} / \mathrm{kg}=69 \pm 35.29 \\
500 \mathrm{mg} / \mathrm{kg}=67 \pm 32.80\end{array}$ & $\begin{array}{l}250 \mathrm{mg} / \mathrm{kg}=-167.6 \pm 23.83 \\
500 \mathrm{mg} / \mathrm{kg}=-169.6 \pm 19.99\end{array}$ \\
\hline & & & n-butanol F & Day 15 & $\begin{array}{l}250 \mathrm{mg} / \mathrm{kg}=132 \pm \\
31.57 \\
500 \mathrm{mg} / \mathrm{kg}=143.8 \pm \\
40.38\end{array}$ & $\begin{array}{l}250 \mathrm{mg} / \mathrm{kg}=-104.6 \pm 17.91 \\
500 \mathrm{mg} / \mathrm{kg}=-92.8 \pm 30.91\end{array}$ \\
\hline & & & Aqueous F & Day 15 & $\begin{array}{l}250 \mathrm{mg} / \mathrm{kg}=104.8 \pm \\
33.16 \\
500 \mathrm{mg} / \mathrm{kg}=109 \pm \\
33.46\end{array}$ & $\begin{array}{l}250 \mathrm{mg} / \mathrm{kg}=-131.8 \pm 20.58 \\
500 \mathrm{mg} / \mathrm{kg}=-127.6 \pm 21.06\end{array}$ \\
\hline & & In glucose loaded mice & Methanol E & Day 15 & $\begin{array}{l}250 \mathrm{mg} / \mathrm{kg}=80.2 \pm \\
17.6 \\
500 \mathrm{mg} / \mathrm{kg}=61.2 \pm \\
16.74 \\
750 \mathrm{mg} / \mathrm{kg}=54.4 \pm \\
14.54\end{array}$ & $\begin{array}{l}250 \mathrm{mg} / \mathrm{kg}=-31.8 \pm 11.17500 \mathrm{mg} / \\
\mathrm{kg}=-51.4 \pm 71 \text { At } 750 \mathrm{mg} / \mathrm{kg}=- \\
60.2 \pm 6.67\end{array}$ \\
\hline \multirow{5}{*}{$\begin{array}{l}\text { Sileshi et al., } \\
2014[7]\end{array}$} & \multirow[t]{5}{*}{ Moringa Stenopetala, } & \multirow{5}{*}{$\begin{array}{l}\text { Alloxan induced swiss } \\
\text { albino mice }\end{array}$} & Ethanol E & $6 \mathrm{~h}$ & $-14.29 \pm 6.65$ & $34.77 \pm 7.54$ \\
\hline & & & Hexane $\mathrm{F}$ & $6 \mathrm{~h}$ & $-25.50 \pm 6.32$ & $23.56 \pm 7.24$ \\
\hline & & & $\begin{array}{l}\text { Dichloromethane } \\
\text { F }\end{array}$ & $6 \mathrm{~h}$ & $-36.56 \pm 7.91$ & $12.50 \pm 8.67$ \\
\hline & & & Butanol F & $6 \mathrm{~h}$ & $-22.76 \pm 12.17$ & $26.30 \pm 12.68$ \\
\hline & & & Aqueous R & $6 \mathrm{~h}$ & $-23.31 \pm 7.82$ & $25.30 \pm 8.41$ \\
\hline \multirow[t]{2}{*}{$\begin{array}{l}\text { Tafesse et al., } \\
2017 \text { [20] }\end{array}$} & \multirow[t]{2}{*}{ Ajuga remota, } & \multirow[t]{2}{*}{ Alloxan-induced mice } & Aqueous E & 14 days & $\begin{array}{l}300 \mathrm{mg} / \mathrm{kg}=-18.73 \pm \\
3.32 \\
500 \mathrm{mg} / \mathrm{kg}=-29.88 \pm \\
1.64\end{array}$ & $\begin{array}{l}300 \mathrm{mg} / \mathrm{kg}=23.27 \pm 4.18 \\
500 \mathrm{mg} / \mathrm{kg}=12.12 \pm 3.03\end{array}$ \\
\hline & & & Ethanol E & 14 days & $\begin{array}{l}300 \mathrm{mg} / \mathrm{kg}=-18.84 \pm \\
2.44 \\
500 \mathrm{mg} / \mathrm{kg}=-19.16 \pm \\
2.36\end{array}$ & $\begin{array}{l}300 \mathrm{mg} / \mathrm{kg}=23.16 \pm 3.52 \\
500 \mathrm{mg} / \mathrm{kg}=22.84 \pm 3.45\end{array}$ \\
\hline \multirow[t]{3}{*}{$\begin{array}{l}\text { Tamiru et al., } \\
2012[28]\end{array}$} & \multirow[t]{3}{*}{$\begin{array}{l}\text { Caylusea abyssinica } \\
\text { (fresen.) fisch. \&Mey. }\end{array}$} & normalmice & Methanolic E & $4 \mathrm{~h}$ & $\begin{array}{l}100 \mathrm{mg} / \mathrm{kg}=9 \pm 5.33 \\
200 \mathrm{mg} / \mathrm{kg}=8 \pm 4.25 \\
300 \mathrm{mg} / \mathrm{kg}=10 \pm 4.30\end{array}$ & $\begin{array}{l}100 \mathrm{mg} / \mathrm{kg}=11 \pm 7.62 \\
200 \mathrm{mg} / \mathrm{kg}=10 \pm 6.91 \\
300 \mathrm{mg} / \mathrm{kg}=12 \pm 6.94\end{array}$ \\
\hline & & $\begin{array}{l}\text { streptozotocin induced } \\
\text { mice }\end{array}$ & & & $\begin{array}{l}100 \mathrm{mg} / \mathrm{kg}=111.67 \pm \\
53.44 \\
200 \mathrm{mg} / \mathrm{kg}=149 \pm \\
41.58 \\
300 \mathrm{mg} / \mathrm{kg}=105.78 \pm \\
51.61\end{array}$ & $\begin{array}{l}100 \mathrm{mg} / \mathrm{kg}=-33.7 \pm 43.36200 \mathrm{mg} / \\
\mathrm{kg}=3.56 \pm 27.45 \\
300 \mathrm{mg} / \mathrm{kg}=-39.66 \pm 41.89\end{array}$ \\
\hline & & Oral glucose loaded rat & & & $\begin{array}{l}100 \mathrm{mg} / \mathrm{kg}=3.83 \pm \\
6.14 \\
200 \mathrm{mg} / \mathrm{kg}=8.17 \pm \\
4.86 \\
300 \mathrm{mg} / \mathrm{kg}=-9.5 \pm \\
12.18\end{array}$ & $\begin{array}{l}100 \mathrm{mg} / \mathrm{kg}=-14 \pm 10.54 \\
200 \mathrm{mg} / \mathrm{kg}=-9.66 \pm 9.85 \\
300 \mathrm{mg} / \mathrm{kg}=-27.33 \pm 14.89\end{array}$ \\
\hline \multirow[t]{2}{*}{$\begin{array}{l}\text { Taye et al., } 2020 \\
{[29]}\end{array}$} & \multirow[t]{2}{*}{ Thymus schimperi } & \multirow[t]{2}{*}{$\begin{array}{l}\text { alloxan induced } \\
\text { diabetic mice }\end{array}$} & Aqueous E & $4 \mathrm{~h}$ & $\begin{array}{l}250 \mathrm{mg} / \mathrm{kg}=-128.6 \pm \\
60.97 \\
500 \mathrm{mg} / \mathrm{kg}=-155 \pm \\
35.71\end{array}$ & $\begin{array}{l}250 \mathrm{mg} / \mathrm{kg}=76.4 \pm 65.45 \\
500 \mathrm{mg} / \mathrm{kg}=49.8 \pm 42.4\end{array}$ \\
\hline & & & Methanol E & & $\begin{array}{l}250 \mathrm{mg} / \mathrm{kg}=-145.6 \pm \\
56.11 \\
500 \mathrm{mg} / \mathrm{kg}=-171.2 \pm \\
28.91\end{array}$ & $\begin{array}{l}250 \mathrm{mg} / \mathrm{kg}=59.2 \pm 60.59 \\
500 \mathrm{mg} / \mathrm{kg}=33.6 \pm 36.86\end{array}$ \\
\hline $\begin{array}{l}\text { Tefera et al., } \\
2020 \text { [30] }\end{array}$ & L. culinaris & Diabetic mice & Methanol E & 21 days & $\begin{array}{l}100 \mathrm{mg} / \mathrm{kg}=- \\
61.34 \pm 4.24 \\
200 \mathrm{mg} / \mathrm{kg}=-71.34 \pm \\
4.79 \\
400 \mathrm{mg} / \mathrm{kg}=-82.25 \pm \\
4.17\end{array}$ & $\begin{array}{l}100 \mathrm{mg} / \mathrm{kg}=49.66 \pm 2.17 \\
200 \mathrm{mg} / \mathrm{kg}=39.66 \pm 3.11 \\
400 \mathrm{mg} / \mathrm{kg}=28.75 \pm 2.03\end{array}$ \\
\hline $\begin{array}{l}\text { Tesfaye et al., } \\
2016 \text { [13] }\end{array}$ & Justicia Schimperiana & Normal mice & Aqueous extract & $4 \mathrm{~h}$ & $\begin{array}{l}200 \mathrm{mg} / \mathrm{kg}=-1 \pm 3.81 \\
400 \mathrm{mg} / \mathrm{kg}=10.17 \pm \\
2.74\end{array}$ & $\begin{array}{l}200 \mathrm{mg} / \mathrm{kg}=-13.33 \pm 4.19 \\
400 \mathrm{mg} / \mathrm{kg}=-2.16 \pm 3.26\end{array}$ \\
\hline
\end{tabular}


Table 3 In vivo anti-diabetic activity of medicinal plat in Ethiopia (Continued)

\begin{tabular}{|c|c|c|c|c|c|c|}
\hline Study & Plant & Animal type & $\begin{array}{l}\text { Extraction } \\
\text { method/ } \\
\text { component }\end{array}$ & $\begin{array}{l}\text { Duration } \\
\text { of } \\
\text { treatment }\end{array}$ & $\begin{array}{l}\text { From diabetic } \\
\text { Control }\end{array}$ & From standard control \\
\hline & & $\begin{array}{l}\text { Streptozocin-induced } \\
\text { mice }\end{array}$ & & & $\begin{array}{l}200 \mathrm{mg} / \mathrm{kg}=2.5 \pm \\
11.70 \\
400 \mathrm{mg} / \mathrm{kg}=39 \pm 11.13\end{array}$ & $\begin{array}{l}200 \mathrm{mg} / \mathrm{kg}=-46.66 \pm 9.33 \\
400 \mathrm{mg} / \mathrm{kg}=-10.16 \pm 8.60\end{array}$ \\
\hline \multirow[t]{2}{*}{$\begin{array}{l}\text { Toma et al., } 2012 \\
\text { [19] }\end{array}$} & \multirow[t]{2}{*}{ Moringa Stenopetala } & Normal & $\begin{array}{l}\text { Butanol } f \text {. of } \\
\text { Ethanol extract }\end{array}$ & 28 days & & $500 \mathrm{mg} / \mathrm{kg}=-2 \pm 18.9$ \\
\hline & & Alloxan Induced Mice & $\begin{array}{l}\text { Butanol } f \text {. of } \\
\text { Ethanol extract }\end{array}$ & & $\begin{array}{l}500 \mathrm{mg} / \mathrm{kg}=77.6 \pm \\
24.11\end{array}$ & $500 \mathrm{mg} / \mathrm{kg}=-2 \pm 18.9$ \\
\hline \multirow[t]{2}{*}{$\begin{array}{l}\text { Tomaet al., } 2015 \\
\text { [9] }\end{array}$} & \multirow[t]{2}{*}{ Moringa Stenopetala } & \multirow[t]{2}{*}{$\begin{array}{l}\text { streptozocin-induced } \\
\text { rats }\end{array}$} & Ethanol fraction & 14 days & $\begin{array}{l}\text { at } 500 \mathrm{mg} / \mathrm{kg}=15.77 \pm \\
3.66\end{array}$ & at $500 \mathrm{mg} / \mathrm{kg}=-2.5 \pm 3.77$ \\
\hline & & & Butanol fraction & & $\begin{array}{l}\text { at } 500 \mathrm{mg} / \mathrm{kg}=13.1 \pm \\
3.18\end{array}$ & at $500 \mathrm{mg} / \mathrm{kg}=-5.17 \pm 3.61$ \\
\hline \multirow{7}{*}{$\begin{array}{l}\text { Tsegayeet al., } \\
2008 \text { [18] }\end{array}$} & \multirow{7}{*}{$\begin{array}{l}\text { Urtica simensis Hochst. } \\
\text { ex. A. Rich } \\
\text { At } 300 \mathrm{mg} / \mathrm{kg} \\
\text { Unit } \mathrm{mg} / \mathrm{dl}\end{array}$} & \multirow{7}{*}{$\begin{array}{l}\text { STZ-induced diabetic } \\
\text { mice }\end{array}$} & Methanol E & $4 \mathrm{~h}$ & $152 \pm 8.36$ & $-131 \pm 19.5$ \\
\hline & & & Aqueous $\mathrm{E}$ & & $147.9 \pm 33.94$ & $-135.6 \pm 38.33$ \\
\hline & & & $\begin{array}{l}\text { Petroleum ether } \\
\text { F. }\end{array}$ & & $10.5 \pm 9.19$ & $-273 \pm 20.05$ \\
\hline & & & Chloroform F. & & $-14.1 \pm 13.95$ & $-297.6 \pm 22.63$ \\
\hline & & & Acetone $\mathrm{F}$. & & $13.7 \pm 21.72$ & $-269.8 \pm 28.09$ \\
\hline & & & Methanol F. & & $105.5 \pm 19.56$ & $-178 \pm 26.31$ \\
\hline & & & Aqueous R & & $201.7 \pm 40.03$ & $-81.8 \pm 44.75$ \\
\hline $\begin{array}{l}\text { Yibruet al., } 2015 \\
\text { [15] }\end{array}$ & Coriandrum Sativum & $\begin{array}{l}\text { STZI nduced T2DM } \\
\text { Mice }\end{array}$ & Ethanol & 21 days & $\begin{array}{l}\text { Increased at 300, } 400 \\
\text { and } 500 \mathrm{mg} / \mathrm{kg}\end{array}$ & Decreased at 300,400 and $500 \mathrm{mg} / \mathrm{kg}$ \\
\hline
\end{tabular}

Three in vitro studies were conducted on four plants (Terminalia brownie Fresen, Moringa Stenopetala, Aloe megalacantha B, and Aloe monticola R.) (Table 1).

\section{In vitro studies}

In vitro half-maximal carbohydrate digestive enzyme inhibitory concentration (IC 50) of Aloe megalacantha B, Aloe monticola R, Moringa Stenopetala, and Terminalia brownie Fresen were evaluated. The IC50 was less than $100 \mu \mathrm{g} / \mathrm{ml}$ except ethanolic extract of Moringa Stenopetala and aqueous extract of Terminalia brownie Fresen. All extract and fractions showed less effect compared to a standard control (acarbose), Table 2.

\section{In vivo studies}

There was a significant difference in duration of treatment among in vivo studies, ranges from $4 \mathrm{~h}$ to 30 days. Fifteen studies used mice, three used rats, and two studies used both rats and mice. In eight of the studies the plant was extracted using methanol, in six ethanol extract and in other six aqueous extract was used, Table 3.

Noteworthy glycemic control was observed with Terminalia brownie Fresen for 14 days, better BSL control compared to a diabetic control. Three studies [22, 24, 26] also showed better reductions in BSL compared to a diabetic control. These studies were conducted respectively for 30,14 and 15 days in Persea Americana, Calpurnia aurea, and Thymus schimperi. Comparable effect to a standard control (glibenclimide) was observed in
Persea Americana and Moringa stenopetala [9, 19, 23, 24]. Better acute glycaemia control was observed in Indigofera spicata Forssk, Thymus schimperi and Urtica simensis Hochst.ex. A. Rich [16, 18, 21].

\section{Clinical studies}

Trigonella foenum-graecum $L$. showed noteworthy effect on lipid profile of newly diagnosed type II diabetic patients [6]. Out of 114, 95 completed the study, 49 in the treatment group and 46 in the control group. Both treatment and control groups had abnormal FBG $(\geq 180 \mathrm{mg} / \mathrm{dL})$ and abnormal lipid profile (TC, TG, HDL-C, and LDL-C) at baseline. Trigonella foenum-graecum administered $(25 \mathrm{mg}$ seed powder solution for 30 consecutive days) showed a significant reduction (13.6\%) in serum TC level as compared to baseline TC level. Yet, no significant difference in TC level in the control group. The treatment group showed a statistically significant decrease $(23.53 \%)$ in serum TG level compared to baseline TG level but the control group had no significant difference in TG level. HDL-C level was significantly increased in the treatment group by $21.7 \%$ as compared to the baseline HDL-C level within the group. LDL-C level had a significantly reduced by $23.4 \%$ as compared to the baseline LDL-C level. Trigonella foenum-graecum produced a significant reduction in $\mathrm{TC}, \mathrm{TG}$, and $\mathrm{LDL}-\mathrm{C}$ levels and an increase in HDL-C level compared to baseline. 


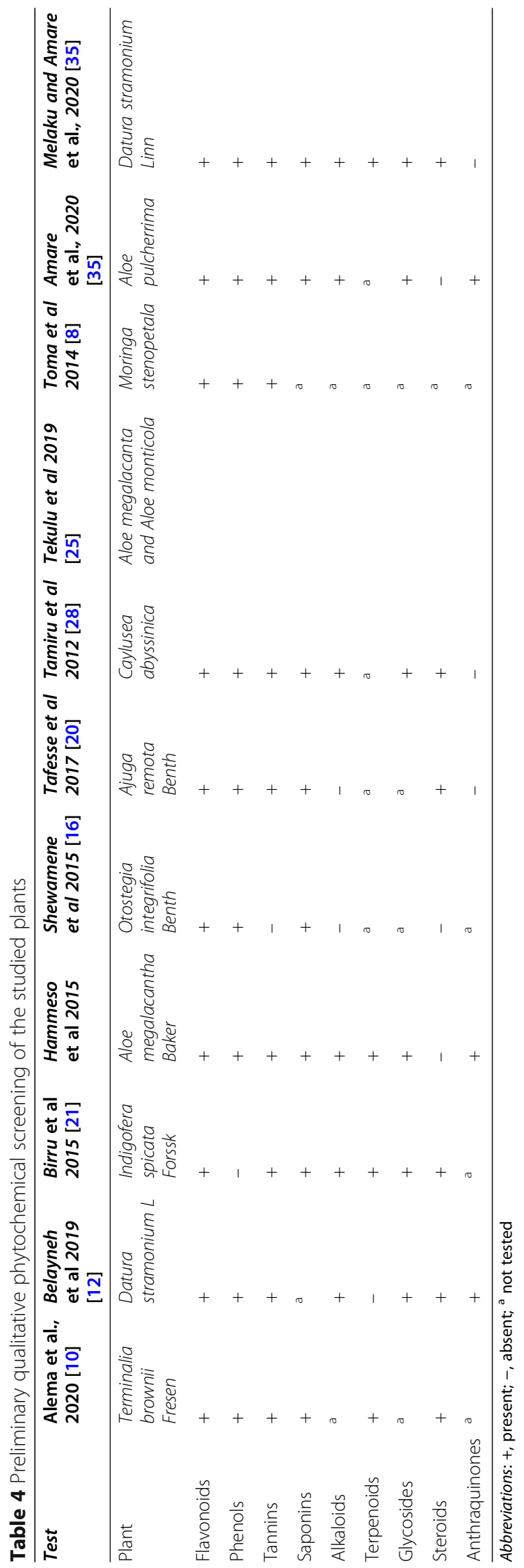




\section{Toxicology}

Acute toxicity studies in animal model demonstrated the relative safety of the plants extract. Seven plants, Terminalia brownie, Calpurnia aurea, Datura stramonium, Indigofera spicata Forssk, Aloe megalacantha, Thymus schimperi, Caylusea abyssinica, Justicia Schimperiana, and Coriandrum Sativum, showed $\mathrm{LD}_{50}$ greater than $2000 \mathrm{mg} / \mathrm{kg}[10,12-15,21,22,26$, 28]. Other plants showed $\mathrm{LD}_{50}$ greater than $5000 \mathrm{mg} /$ $\mathrm{kg}[11,16,19,20,23]$. The LD50 of Moringa stenopetalla were $50.6 \mathrm{~g} / \mathrm{kg}$ [11] and $50 \mathrm{~g} / \mathrm{kg}$ [23]. The $\mathrm{LD}_{50}$ of Persea Americana was greater $1000 \mathrm{mg} / \mathrm{kg}$ [23]. The sub-chronic toxicity of Moringa Stenopetala showed normal hematological, significantly higher platelet counts compared to controls, significant changes were observed in the clinical chemistry parameters (urea, creatinine, CA125, TSH, FT3, ALT, TGs, and cholesterol), FT4 significantly reduced, and AST were significantly higher in the mice received the treatment [7].

\section{Phytochemistry}

Preliminary phytochemical investigation were given in Table 4 and Tekulu et al, 2019 [25] further studied TLC isolates, AM1 and AG1, separated from leaves latexes of A. megalacantha and A. monticola respectively. AM1 and AG1are considered to be more polar compounds than AM2 and AG2 as they have small Rf values during isolation using silica gel coated TLC plate with chloroform: methanol (80:20) solvent system [25]. They could be assigned as glycosides of anthraquinones or its derivatives as they have similar $\mathrm{R} f$ with previously isolated anthraquinone glycosides from leaf latex and root extracts of different Aloe species [38-40].

\section{Discussion}

This study reviewed twenty three articles on plants with anti-diabetic activity. Most of the studies (20) were conducted in an animal model, in vitro studies (2) and both in vitro and in vivo study (1). Noteworthy glycemic control was observed with $T$. brownie Fresen compared to a diabetic control. Carbohydrate digestion inhibitory effect was demonstrated in in vitro studies. The possible mechanism for hypoglycemic effect could be decreasing the absorption of ingested sugars as shown in in vitro $\alpha$ amylase $/ \alpha$-glucosidase inhibitory activity. The human study was primarily focused on the effect of body weight and lipid profile in patients with type 2 diabetes mellitus [6]. Numbers of studies conducted on anti-diabetic activity of Ethiopian medicinal plants were lower compared to studies conducted in many African countries. For example, a systematic review in Nigeria showed 103 plants have experimental evaluation of their blood sugar reducing effects, either in vivo or in vitro [41].
Several medicinal plants are being used traditionally for treatment of diabetes mellitus in Ethiopia for a long period of time but the number of plants studied is limited. This review summarized studies conducted so far and highlighting the need for further studies. Moringa stenopetala is the most commonly studied plant and other plants remain scantly studied. Inhibition of $\alpha$ amylase, a potential target to control diabetes mellitus for more than 30 years is considered a strategy for the treatment of diabetes mellitus [42].

The effect exerted by Moringa stenopetala could most probably be carbohydrate absorption inhibition resulting in hypoglycemia which could give an insight into the mechanism of the hypoglycemic activity of the antidiabetic plants. Herbal medicines are often complex mixtures of various phytochemicals that work synergistically to achieve a desired therapeutic outcome [43] and therefore several mechanisms of action could be expected including protecting and repairing cells. The mechanism of lowering BSL could also be stimulating insulin secretion and action.

Natural products are promising lead candidates for discovering and also easily available, affordable and tolerable $[44,45]$. Plants provide a rich source of bioactive molecules and possess diverse pharmacological actions including anti-diabetic activity. The activity is attributed to either a single component or mixture of phytochemicals. The phytochemicals responsible for anti-diabetic properties could mainly be alkaloids, phenolics, flavonoids, glycosides, saponins, polysaccharides, stilbenes, and tannins [46] and phytochemical investigation of current study showed the presence of this component in most studied plants. Several animal studies reported a wide variation in composition between the extraction methods. Phytochemical compositions are also highly dependent on several endogenous and exogenous factors, environment, genetics, and plant part used, growing, drying, and storing conditions [47].

Investigations of phytochemicals responsible for the anti-diabetic activity have progressed in the last few decades and treating diabetes mellitus with plantderived compound seems highly attractive as they are accessible and do not require laborious pharmaceutical synthesis.

\section{Strengths and limitation of the studies}

The evidence synthesized from in vitro/ in vivo studies will have paramount for further studies in human studies. It will show directions of further the studies and promote the traditional use. The limitation of this study arises from the limitation of the included primary studies. The methods used for the induction of diabetic mellitus were streptozotocin or alloxan which mostly 
induces type 1 diabetes mellitus. The methodological challenge in an animal model study is as induction method mostly induces type 2 diabetes mellitus. With its limitation this study provides preliminary activity assay showed further study direction in other plants, identification and isolation of most active components that could join the adventure of modern drug discovery.

It is also worth noting that only one plant has been studied for efficacy in humans in Ethiopia. No clinical trials were conducted and also no clearly defined preparation for clinical trials in Ethiopia. Furthermore, majority of studies did not report the composition of the formulation, standardization protocols and preparation procedures.

\section{Conclusion}

This review demonstrated medicinal plants used for management of diabetes mellitus in Ethiopia are worthy for further investigation of pharmacologically active ingredients and clinical study. Further in vitro, in vivo and clinical studies are warranted to confirm the claimed activity of commonly used medicinal plant species. Studies should also focus on the identification of the active ingredient(s) of potent plant species for the development of modern medicine. The present review provides useful information to researchers, students, health professionals, policymakers and, traditional medicine practitioners.

\section{Supplementary Information}

The online version contains supplementary material available at https://doi. org/10.1186/s40816-021-00251-x.

\section{Additional file 1.}

\section{Abbreviations}

BSI: Blood sugar level; TC: Total cholesterol; TG: Total glyceraldehydes; LDLC: Low density lipoprotein cholesterol; HDL-C: High density lipoprotein cholesterol; T1DM: Type 1 diabetes mellitus; T2DM: Type 2 diabetes mellitus; STZ: Streptozotocin; Cl: Confidence interval; Rf: Retention factor; LD 50 : Median lethal dose

\section{Acknowledgments}

Not applicable.

\section{Authors' contributions}

SD conceived the idea and designed the study. KE, SS and EW searched literature extracted data and drafted manuscript. SD drafted the manuscript. All authors reviewed and approved the final manuscript.

\section{Funding}

No funding.

\section{Availability of data and materials}

The data supporting the conclusions of this article are included within the article and its supplementary files.

Ethics approval and consent to participate Not applicable.
Consent for publication

Not applicable.

\section{Competing interests}

The authors declare that they have no competing interests.

\section{Author details}

${ }^{1}$ Pharm-BioTechnology and Traditional Medicine Center of Excellence (PHAR MBIOTRAC), Mbarara University of Science and Technology, P.O. Box 1410, Mbarara, Uganda. ${ }^{2}$ School of Pharmacy, Faculty of Medicine, College of Medicine and Health Sciences, Hawassa University, P. O. Box 1560, Hawassa, Ethiopia. ${ }^{3}$ Department of Biochemistry, Faculty of Medicine, College of Medicine and Health Sciences, Hawassa University, P. O. Box 1560" Hawassa, Ethiopia. ${ }^{4}$ Department of Anatomy, Faculty of Medicine, College of Medicine and Health Sciences, Hawassa University, P. O. Box 1560 "Hawassa, Ethiopia.

Received: 23 July 2020 Accepted: 11 January 2021

Published online: 02 February 2021

\section{References}

1. Goldenberg R, Punthakee Z. Definition, classification and diagnosis of diabetes, prediabetes and metabolic syndrome. Can J Diabetes. 2013;37: S8-11.

2. Fowler MJ. Microvascular and macrovascular complications of diabetes. Clin Diabetes. 2011;29:116-22.

3. Organization WH. WHO congress on traditional medicine 2008: Beijing declaration 2011

4. Belayneh A, Asfaw Z, Demissew S, Bussa NF. Medicinal plants potential and use by pastoral and agro-pastoral communities in Erer Valley of Babile Wereda, Eastern Ethiopia. J Ethnobiol Ethnomed. 2012:8:42.

5. Moher D, Liberati A, Tetzlaff J, Altman DG. Preferred reporting items for systematic reviews and meta-analyses: the PRISMA statement. Int I Surg. 2010;8:336-41

6. Geberemeskel GA, Debebe YG, Nguse NA. Antidiabetic Effect of Fenugreek Seed Powder Solution (Trigonella foenum-graecum L.) on Hyperlipidemia in Diabetic Patients. J Diabetes Res. 2019. https://doi.org/10.1155/2019/ 8507453.

7. Sileshi T, Makonnen E, Debella A, Tesfaye B. Antihyperglycemic and subchronic toxicity study of Moringa stenopetala leaves in mice. J Coast Life Med. 2014;2:214-21.

8. Toma A, Makonnen E, Mekonnen Y, Debella A, Addisakwattana S. Intestinal a-glucosidase and some pancreatic enzymes inhibitory effect of hydroalcholic extract of Moringa stenopetala leaves. BMC Complement Altern Med. 2014;14:1-5. https://doi.org/10.1186/1472-6882-14-180.

9. Toma A, Makonnen E, Mekonnen Y, Debella A, Adisakwattana S. Antidiabetic activities of aqueous ethanol and n-butanol fraction of Moringa stenopetala leaves in streptozotocin-induced diabetic rats. BMC Complement Altern Med. 2015;15:1-8. https://doi.org/10.1186/s12906-0150779-0.

10. Alema NM, Periasamy G, Sibhat GG, Tekulu GH, Hiben MG. Antidiabetic activity of extracts of Terminalia brownii fresen. Stem bark in mice. J Exp Pharmacol. 2020;12:61-71.

11. Mussa A, Makonnen E, Urga K. Effects of the crude aqueous extract and isolated fraction of Moringa stenopetala leaves in normal and diabetic mice. Pharmacologyonline. 2008;3:1049-55.

12. Belayneh YM, Birhanu Z, Birru EM, Getenet G. Evaluation of in vivo antidiabetic, antidyslipidemic, and in vitro antioxidant activities of hydromethanolic root extract of Datura stramonium L. (Solanaceae). J Exp Pharmacol. 2019;11:29-38.

13. Tesfaye A, Makonnen E, Gedamu S. Hypoglycemic and antihyperglycemic activity of aqueous extract of Justicia Schimperiana leaves in normal and streptozotocin-induced diabetic mice. Int J Pharma Sci Res. 2016:7:107-13.

14. Hammeso WW, Emiru YK, Getahun KA, Kahaliw W. Antidiabetic and antihyperlipidemic activities of the leaf latex extract of Aloe megalacantha baker (Aloaceae) in Streptozotocin-induced diabetic model. Evidence-based Complement Altern Med. 2019. https://doi.org/10.1155/2019/8263786.

15. Yibru E, CMenon MK, Belayneh Y, Seyifu D. The effect of Coriandrum Sativum seed extract on hyperglycemia, lipid profile and renal function in streptozotocin induced type- 2 diabetic Swiss albino mice. Int J Heal Sci Res. 2015;5:166-77. 
16. Shewamene Z, Abdelwuhab M, Birhanu Z. Methanolic leaf exctract of Otostegia integrifolia Benth reduces blood glucose levels in diabetic, glucose loaded and normal rodents. BMC Complement Altern Med. 2015;15:1-7. https://doi.org/10.1186/s12906-015-0535-5.

17. Makonnen E, Hunde A, Damecha G. Hypoglycaemic effect of Moringa stenopetala aqueous extract in rabbits. Phyther Res. 1997;11:147-8.

18. Tsegaye W, Urga K, Asres K. Antidiabetic activity of Samma (Urtica simensis Hochst. Ex. A. Rich.) in streptozotocin-induced diabetic mice. Ethiop Pharm J. 2008;27:75-82

19. Toma A, Makonnen E, Debella A, Tesfaye B. Antihyperglycemic effect on chronic administration of butanol fraction of ethanol extract of Moringa Stenopetala leaves in alloxan induced diabetic mice. Asian Pac J Trop Biomed. 2012. https://doi.org/10.1016/S2221-1691(12)60461-4.

20. Tafesse TB, Hymete A, Mekonnen Y, Tadesse M. Antidiabetic activity and phytochemical screening of extracts of the leaves of Ajuga remota Benth on alloxan-induced diabetic mice. BMC Complement Altern Med. 2017;17:1-9.

21. Birru EM, Abdelwuhab M, Shewamene Z. Effect of hydroalcoholic leaves extract of Indigofera spicata Forssk. On blood glucose level of normal, glucose loaded and diabetic rodents. BMC Complement Altern Med. 2015; 15:1-8. https://doi.org/10.1186/s12906-015-0852-8.

22. Belayneh YM, Birru EM. Antidiabetic activities of hydromethanolic leaf extract of Calpurnia aurea (Ait.) benth. Subspecies aurea (Fabaceae) in mice. Evidence-based Complement Altern Med. 2018. https://doi.org/10.1155/ 2018/3509073

23. Nardos A, Makonnen E, Debella A. Effects of crude extracts and fractions of Moringa stenopetala (baker f) cufodontis leaves in normoglycemic and alloxan-induced diabetic mice. African J Pharm Pharmacol. 2011;5:2220-5.

24. Mahadeva Rao US, Adinew B. Remnant B-cell-stimulative and anti-oxidative effects of Persea Americana fruit extract studied in rats introduced into streptozotocin - induced hyperglycaemic state. African J Tradit Complement Altern Med. 2011;8:210-7.

25. Tekulu GH, Araya EM, Mengesha HG. In vitro a-amylase inhibitory effect of TLC isolates of Aloe megalacantha baker and Aloe monticola Reynolds. BMC Complement Altern Med. 2019;19:1-7.

26. Shewasinad A, Bhoumik D, Hishe HZ, Masresha B. Antidiabetic activity of methanol extract and fractions of Thymus schimperi Ronniger leaves in Normal and Streptozotocin induce diabetic mice. Iran J Pharmacol Ther. 2019;16:1.

27. Seifu D, Gustafsson LE, Chawla R, Genet S, Debella A, Holst M, et al. Antidiabetic and gastric emptying inhibitory effect of herbal Melia azedarach leaf extract in rodent models of diabetes type 2 mellitus. J Exp Pharmacol. 2017:9:23.

28. Tamiru W, Engidawork E, Asres K. Evaluation of the effects of $80 \%$ methanolic leaf extract of Caylusea abyssinica (fresen.) fisch. \& Mey. on glucose handling in normal, glucose loaded and diabetic rodents. BMC Complement Altern Med. 2012;12:1. https://doi.org/10.1186/1472-6882-12 151.

29. Taye GM, Bule M, Gadisa DA, Teka F, Abula T. In vivo antidiabetic activity evaluation of aqueous and $80 \%$ methanolic extracts of leaves of thymus schimperi (Lamiaceae) in alloxan-induced diabetic mice. Diabetes, Metab Syndr Obes Targets Ther; 2020. https://doi.org/10.2147/DMSO.S268689.

30. Tefera MM, Masresha Altaye B, Yimer EM, Berhe DF, Bekele ST. Antidiabetic effect of germinated lens culinaris medik seed extract in streptozotocininduced diabetic mice. J Exp Pharmacol. 2020. https://doi.org/10.2147/JEP. S228834.

31. Melaku BC, Amare GG. Evaluation of antidiabetic and antioxidant potential of hydromethanolic seed extract of Datura stramonium Linn (Solanaceae). J Exp Pharmacol. 2020. https://doi.org/10.2147/JEP.S258522

32. Kifle ZD, Anteneh DA, Atnafie SA. Hypoglycemic, anti-hyperglycemic and anti-hyperlipidemic effects of Bersama abyssinica Fresen (Melianthaceae) leaves' solvent fractions in normoglycemic and streptozotocin-induced diabetic mice. J Exp Pharmacol. 2020. https://doi.org/10.2147/JEP.S273959.

33. Mahadeva RUS, Adinew B. Hypolipidemic effect of dichloromethane as well as methanolic fruit and leaf extract of Ethiopian alligator pear (persea americana mill.) on tyloxapol-induced hyperlipidemic experimental rat. Asian J Res Chem. 2011;4(4):574-8.

34. Kifle ZD, Enyew EF. Evaluation of in vivo antidiabetic, in vitro a-amylase inhibitory, and in vitro antioxidant activity of leaves crude extract and solvent fractions of Bersama abyssinica Fresen (Melianthaceae). J EvidenceBased Integr Med. 2020. https://doi.org/10.1177/2515690X20935827.
35. Amare GG, Meharie BG, Belayneh YM. Evaluation of antidiabetic activity of the leaf latex of Aloe pulcherrima Gilbert and Sebsebe (Aloaceae). EvidenceBased Complement Altern Med. 2020. https://doi.org/10.1155/2020/ 8899743.

36. Mekuria AB, Belachew SA, Tegegn HG, Ali DS, Netere AK, Lemlemu E, et al. Prevalence and correlates of herbal medicine use among type 2 diabetic patients in teaching Hospital in Ethiopia: a cross-sectional study. BMC Complement Altern Med. 2018;18:1-8. https://doi.org/10.1186/s12906-0182147-3.

37. Abdulkadir J. Intake of traditional taenicidal drugs among diabetics and non-diabetics. Ethiop Med J. 1979;17(3):75-80.

38. Cock IE. The Genus Aloe: Phytochemistry and Therapeutic Uses Including Treatments for Gastrointestinal Conditions and Chronic Inflammation. In: Rainsford K, Powanda M, Whitehouse M, editors. Novel Natural Products: Therapeutic Effects in Pain, Arthritis and Gastro-intestinal Diseases. Progress in Drug Research, vol 70. Basel: Springer; 2015. https://doi.org/10.1007/9783-0348-0927-6_6

39. Abdissa N, Gohlke S, Frese M, Sewald N. Cytotoxic compounds from aloe megalacantha. Molecules. 2017;22:1136.

40. Geremedhin G, Bisrat D, Asres K. Isolation, characterization and in vivo antimalarial evaluation of anthrones from the leaf latex of Aloe percrassa Todaro. J Nat Remedies. 2014;14:119-25.

41. Ezuruike UF, Prieto JM. The use of plants in the traditional management of diabetes in Nigeria: pharmacological and toxicological considerations. J Ethnopharmacol. 2014;155:857-924. https://doi.org/10.1016/j.jep.2014.05.055.

42. Sales PM, Souza PM, Simeoni LA, Magalhães PO. Silveira D a-amylase inhibitors: a review of raw material and isolated compounds from plant source. J Pharm Sci. 2012;15:141-83.

43. Joan IA, Campbell-Tofte PM. Kaj Winther Harnessing potential clinical use medicinal Plants as anti-diabetic agents Botanicals. Targets Ther. 2012. https://doi.org/10.2147/BTAT.S17302.

44. Nwaka S, Hudson A. Innovative lead discovery strategies for tropical diseases. Nat Rev Drug Discov. 2006:5:941-55.

45. Lee K-H. Current developments in the discovery and design of new drug candidates from plant natural product leads. J Nat Prod. 2004;67:273-83.

46. Vinayagam R, Xiao J, Xu B. An insight into anti-diabetic properties of dietary phytochemicals. Phytochem Rev. 2017;16:535-53.

47. Akula R, Ravishankar GA. Influence of abiotic stress signals on secondary metabolites in plants. Plant Signal Behav. 2011;6:1720-31.

\section{Publisher's Note}

Springer Nature remains neutral with regard to jurisdictional claims in published maps and institutional affiliations.

\section{Submit your manuscript to a SpringerOpen ${ }^{\circ}$ journal and benefit from:}

- Convenient online submission

- Rigorous peer review

- Open access: articles freely available online

- High visibility within the field

- Retaining the copyright to your article

Submit your next manuscript at $>$ springeropen.com 